\title{
The Efficacy of Medical Consultation to Improve Oral Health Outcomes in Patients with Sickle Cell Disease
}

\section{Gail Cherry-Peppers ${ }^{1 *}$, Andrea D Jackson ${ }^{2}$, Cheryl Fryer ${ }^{1}$, Candice Mitchell ${ }^{1}$, Xinbin Gu$^{3}$, Dana C Jackson ${ }^{4}$, Robert Gamble ${ }^{1}$, Albert Cheek ${ }^{1}$, Gillian Robinson- Warner ${ }^{1}$, Meirong Liu ${ }^{5}$, Romella Rodgers ${ }^{6}$, Floydstyne Williams $^{6}$, Courtney Ford ${ }^{7}$, Gretchen Peppers ${ }^{7}$ Lee Goodloe $^{7}$, John Atere $^{7}$, Thomas Savage ${ }^{7}$ and Phillip Woods ${ }^{8}$}

${ }^{1}$ Research Committee, Doctor of Dental Surgery, Office of the Dean, Howard University College of Dentistry, Washington, DC. United States of America (USA)

${ }^{2}$ Dean, Howard University College of Dentistry, Washington, DC, USA

${ }^{3}$ Associate Dean for Research, Chair, Research Committee, Howard University College of Dentistry, Washington, DC, USA

${ }^{4}$ Chair and Program Director Oral and Maxillofacial Surgery, Howard University

Hospital, Washington, DC, USA

${ }^{5}$ Research Committee, Associate Professor, School of Social Work, Howard University, Washington, DC, USA

${ }^{6}$ Project Coordinators, Howard University College of Dentistry, Washington, DC, USA

${ }^{7}$ Summer Student Research Committee, Howard University College of Dentistry/Howard University College Medicine, and Undergraduate Programs, Washington, DC, USA

${ }^{8}$ Volunteer Clinical Consultant, Howard University College of Dentistry, Washington, DC, USA

*Corresponding Author: Gail Cherry-Peppers, Associate Professor, Department of Restorative Dentistry, Director, Community Services, Howard University College of Dentistry, Washington, DC, USA.
Received: December 01, 2020

Published: December 28, 2020

(C) All rights are reserved by Ramakant

Gupta., et al.

\begin{abstract}
Sickle Cell Disease is a complex genetic disorder resulting from the presence of a mutated form of hemo-globin. Morbidity, frequency of crisis, degree of anemia, and organ systems involved vary considerably per patient. Dental health professionals and other specialists commonly request comprehensive medical consultations prior to performing complex periodontal, endodontic, and surgical procedures. It is of great benefit to have a very detailed medical consultation and history of treatment in order to have successful dental outcomes and minimize post-treatment dental complications. This review is to raise awareness about the impact of oral diseases in patients with sickle cell disease and to emphasize the importance of full medical disclosure and a well-documented medical status report which can guide treatment planning and greatly improve the course of dental treatment.
\end{abstract}

Keywords: Sickle Cell Disease; Sickle Cell Trait; Oral Health 


\section{Introduction}

Sickle Cell Disease is a very complex disease in which there is significant variation with patients. Approximately 100,000 individuals are living with sickle cell disease, and 1 in 365, African-American births have sickle cell disease. Sickle cell disease occurs among about 1 out of every 16,300 Hispanic-American births. About 1 in 13 African-American babies are born with sickle cell trait (SCT). Sickle cell disease (SCD) is a common hemoglobinopathy among African Americans and Hispanics in the United States, as well as the Middle East, the Afro-Caribbean region, the Mediterranean and East India. Life expectancy in persons with SCD is forty years of age. In Africa, and some countries such as Cameroon, Republic of Congo, Gabon, Ghana and Nigeria the prevalence is between $10 \%$ to $30 \%$ while in some parts of Uganda it is much higher. Some of the children with the most severe form of the disease may die before five years of age, usually from an infection or splenic sequestration [1]. In the United States, penicillin prophylaxis, vaccines against pneumococcal diseases and the use of hydroxyurea have been key mitigating factors in pediatric SCD morbidity and mortality.

The defective gene $(\mathrm{HbS})$ identified on chromosome II, determines an amino acid substitution in the sixth position of the beta hemoglobin chain. This single point mutation of valine for glutamic acid results in a loss of two negative charges, leading to protein surface abnormalities [2]. During deoxygenation under conditions of low oxygen tension, sickle-cell hemoglobin is less soluble than normal hemoglobin $[3,4]$, resulting in the formation of aggregates and fibers within the red cell, giving rise to morphologic changes [3-5]. This distortion of the erythrocyte into a sickle shape increases cellular rigidity, causes membrane damage with the potential of irreversible sickling, and impairs the transit of the erythrocyte through microcirculation [2-4]. The initiation and progression of sickle cell disease is incited by a group of inherited red blood cell disorders that affects hemoglobin, leading to serious problems, including stroke, eye problems, infections and episodes of pain, or painful crises [6], and increased dental conditions. Having sickle cell disease also raises the risk for severe co-morbidities $[7,8]$.

\section{Medical consults and other treatment considerations}

All dental health professionals who treat patients with sickle cell disease should review the complete health status of the patient. It is important to consider requesting laboratory reports, in addition to a full narrative when pursuing consultation for sickle cell disease patients in need of extensive dental procedures [9]. Medical professionals should provide a detailed summary in the medical consultation report, as requested, by organ system affected [5]. As the population of individuals with sickle cell disease is living longer in an environment of advanced technology, many dental post treatment complications can be minimized when there is accurate sharing of information between the patient's medical team and dentist. Detailed medical consultations will afford the dentist an opportunity to adjust treatment planning and execution and avoid serious complications $[9,10]$. Many dentists have experienced limited or poorly written medical consults which may lead to numerous complications and delays in dental treatment. The impact of oral diseases can lead to a sharp decline in the overall health of the sickle cell patient. Serious infections, dental caries, increased risk of periodontal disease, slow healing, prolonged bleeding, extensive loss of teeth, pain-related conditions of the jaw, osteomyelitis (limited) and post-surgical hospitalizations are some of the most common adverse dental conditions in patients with sickle cell disease [8].

Well defined clinical procedures that include comprehensive details of dental services to be rendered should be sent to the patients' physician [11]. Key findings should be noted such as the extensiveness and type of surgery, number and type of extractions, removal of exostoses, and complex surgical and periodontal procedures in order for the patients' physician to have a full understanding of what is going to be done. The type of anesthesia (general anesthesia, IV sedation or nitrous oxide) should also be included in the consult request. Medication interactions may also be of concern during dental appointments. Effects of many of the medications for the treatment of sickle cell disease such as infusion medications can include oropharyngeal pain, joint and muscle pain, fatigue, pruritus, urticaria, sweating, and possibly shortness of breath. Requests for information about recent transfusions, as well as the frequency of crises, may vary per patient. Good practice may include consulting the patients' hematologist. In general, close working relationships between the dentist and medical team are important for successful outcomes $[9,11]$.

Environmental factors often play a role in the occurrence of painful attacks. Common triggers include severe dental caries, periodontal diseases, dental infections, lengthy dental procedures, prolonged dental anesthesia, cold temperatures, dehydration, ex- 
cessive amounts of exercise and tobacco smoke. Other triggers such as plane flights and high altitudes can also trigger an attack $[1,12]$. While research on sickle cell disease and health status has included a broad spectrum of chronic and acute conditions, relatively little attention has been given to the social impact of oral health problems. Traditionally, oral health has been measured on the basis of tissue pathology with limited recognition of the broader social implications [13]. Yet dental problems are characterized by high prevalence and high unmet need among both children and adults with sickle cell disease.

\section{Systemic implications}

Periodic exacerbation of sickling raises blood viscosity, blocks capillaries, and results in tissue ischemia and bone marrow infarcts. High morbidity and mortality are associated with the homozygous disease [6]. Acute vaso-occlusive crisis (VOC), another complication of sickle cell disease, results from tissue ischemia related to vascular occlusion $[8,10]$. It's characterized by excruciating pain - usually of sudden onset, although gradual onset is also possible. Patients with sickle cell disease may experience VOC at some point, but the frequency is variable and unpredictable. This in turn results both in vasculature damage, tissue hypoxia, and may ultimately lead to tissue clots which can cause extreme pain in the back, chest, hands and feet. The disrupted blood flow can also cause damage to bones, muscles and organs. Most sickle cell disease patients often feel weak, tired and look pale. Other common findings include retinal vascular changes, and areas of the skin may often have a yellowish tint. During a sickle-cell crisis, pain occurs primarily in the long bones, chest and abdomen. The patient may also experience fever, jaundice, tachycardia, tachypnea, abdominal tenderness and hypertension $[3,10,13]$.

The chronic vasculature damage subsequently leads to diseases of the bone, kidney, heart, lung, eye and other organs [2,3,6,14]. Bony abnormalities include infarction with step-like depressions, widening of medullary spaces from increased hematopoiesis, and thinning of the cortices. Necrosis of the femoral head may be positively associated with a silent but progressive occlusion of the microcirculation, with subsequent increased intraosseous pressure and osteoblastic death [15]. Initially, the necrosis of bone marrow and associated bone-forming cells is brought about by localized sludging of sickled cells in narrowed sinusoids. While repair processes may then lead to healing, increased intramedullary pressure may result, ultimately leading to the bone resorption [2,15]. Silent cerebral infarcts and strokes associated with cognitive and neurological impairment may occur in children and adults [7].

Common infections in patients with sickle cell disease include pneumonia, meningitis, septicemia and osteomyelitis [5,6]. Infection is one of the major causes of death of children with sickle-cell disease and also accounts for significant morbidity and mortality in adults $[16,17]$. The increased susceptibility to infection is related to the absence of splenic function and, in some cases, to an abnormality of the properdin opsonization pathway [14].Other precipitating events include hypoxia, acidosis, dehydration, systemic disease, trauma, exposure to cold, surgery and strenuous exercise $[3,14]$. Infections can also be precipitating causes of sickle-cell crises [16].

\section{Common dental findings}

Oral manifestations include mucosal pallor from chronic anemia, delayed eruption of teeth, and hypoplasia of enamel [18]. Soni [19] reported hypomineralization of dentin, abrupt alterations of dentinogenesis, and hypercementosis in a small group of subjects with sickle cell disease. Andrews [20] reported five patients who exhibited osseous changes in teeth without pathogenesis [19]. Other reported radiographic findings in sickle cell disease patients included: increased lamina dura, a step-ladder appearance of bone trabeculae, large and irregularly shaped marrow spaces, and the presence of pulp stone inclusions [5,21,22]. Patton [21] and Shroyer [22] reported osteomyelitis of the mandible following sickle-cell crises. Osteomyelitis probably occurs secondary to the repeated bony infarcts that can form a nidus for infection [5]. In general, bone changes observed in the jaws of patients with sickle cell disease can be classified as 1) radiopaque areas associated with previous vaso-occlusive incidents, 2) osteomyelitis due to infections, and 3) regions with osteoporosis arising from bone marrow hyperplasia $[3,23]$. A routine maintenance preventive care schedule is of benefit to sickle cell patients to decrease unintended health consequences. 


\section{Case Report}

The following is a case of neuropathy in a patient with sickle cell disease who presented with a toothache. Successful treatment was rendered. Ongoing communication with the patients' physician and a detailed narrative were provided prior to treatment. Communication with the physician was a key factor in post-operative management.

A middle-aged black female presented for evaluation of pain in the left jaw. The patient stated that she had intermittent pain in the jaw for the past three years, and was being transfused every 6 to 8 weeks as her hemoglobin and hematocrit declined. By history, her dental pain was associated with minor crises and prior to transfusions. The pain was not associated with hot or cold sensitivity and could not be localized to one tooth. After transfusion, the tooth pain remitted. The patient had minimal problems with crises, and the predominant feature of her sickle cell disease was anemia and chronic pain. In addition to pain in the mandibular area, she complained of minor, intermittent pain of the legs, lower back pain and peripheral pain. The past medical history included subarachnoid hemorrhage and seizures, membranoproliferative glomerulonephritis and frequent urinary tract infections. Intraoral and extraoral examinations were performed. No significant lymphadenopathy was noted. The oral mucosa as slightly icteric. Soft and hard tissue examinations were within normal limits.

The most likely diagnosis of the radiolucent/radiodense mass in the left mandible was osteomyelitis.

The area has remained unchanged and the patient had evidence of other sites of bone abnormalities. Abnormal bone is frequently seen in sickle cell disease and occurs from vascular occlusion. The pain in the jaw was thought to be secondary to occlusion of the microvasculature, rather than from an odontogenic source. Neuropathies and pain in other parts of the body are reported in areas where the microvasculature is occluded, such as the head of the femur [14]. The radiolucent area apical to \#18 and \#19 and was most likely secondary to extreme medullary hematopoiesis, which is also common in sickle cell disease.
The sclerotic area was not biopsied, as to not introduce bacteria into boney areas that could be susceptible to osteomyelitis. Other than management of pain by analgesics, further definitive treatment was not required, and the patient was followed for ominous clinical and radiographic changes, such as expansion of the mandible or root resorption. The patient continuously seeks dental care.

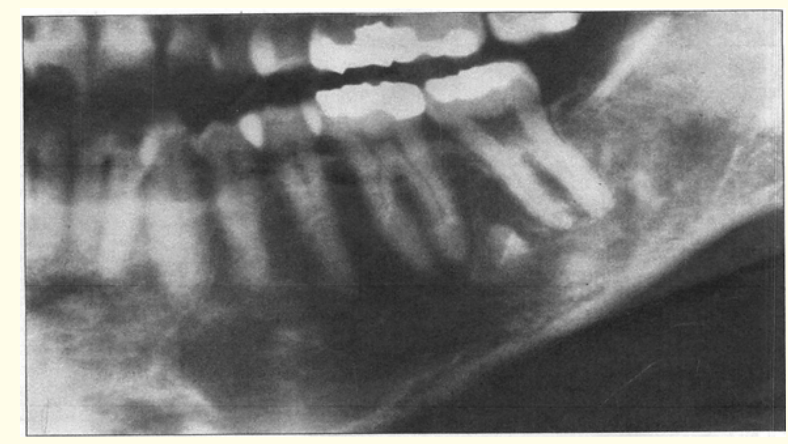

Figure 1: Panoramic radiograph revealing proliferation of the radiolucent/radiodense area apical to and around the roots of $\# 18$ and \#19. The lesion is $3 \mathrm{~cm}$ in diameter.

\section{Bibliography}

1. www.scdsilentdamage.com

2. Mohler ON and Thorup OA. "Hemolytic anemia". In: Thorup OA, ed. Fundamentals of Clinical Hematology. Philadelphia: WB Saunders (1987): 251-348.

3. Jandl JH. "Abnormal hemoglobin and hemoglobinopathies". In: Blood Pathophysiology. Boston: Blackwell Scientific (1991): 182-195.

4. Dean J and Schecter AN. "Sickle-cell anemia: Molecular and cellular bases of therapeutic approaches (Part 10.)". New England Journal Medicine 299 (1978): 752-763.

5. Natrajan K and Kutlar A. "Disorders of the Hemoglobin Structure Sickle Cell Anemia and Related Abnormalities”. Kaushansky K., Lichtman M.A., Prchal J.T., Levi M.M., and Press O.W., and Burns L.J., and Caligiuri M, Eds. Williams Hematology, 9e. McGraw-Hill. (2015): 2-66. 
6. Beutler E. "Erythrocyte disorders; anemias related to abnormal hemoglobin". In: Williams WJ, Beutler E, Erslev AJ, Lichtman MA. eds. Hematology. New York: McGraw-Hill (1983): 583-608.

7. Chekroun M., et al. "Oral manifestations of sickle cell disease". British Dental Journal 226.1 (2018): 27-31.

8. https://www.nhlbi.nih.gov/health-topics/sickle-cell-disease

9. Cherry-Peppers G., et al. "Sickle cell anemia: a case report and literature review". Journal of Clinical and Preventive Dentistry 14.4 (1992): 5-9.

10. Lentz MB and Kautz DD. "Acute vaso-occlusive crisis in patients with sickle cell disease". Nursing 47.1 (2017): 67-68.

11. Laurence B., et al. "Dental infections increase the likelihood of hospital admissions among adult patients with sickle cell disease". Community Dental Health 30.3 (2013): 168-172.

12. Hsu LL and Fan-Hsu J. "Evidence-based dental management in the new era of sickle disease". Journal of the American Dental Association 151.9 (2020): 668-677.

13. Mulimani P., et al. "Treatment of dental complications in sickle cell disease". Cochrane Database of Systematic Reviews Art. No.: CD011633. John Wiley and Sons, Ltd., 4 (2016).

14. Forget BG. "Sickle-cell anemia and associated hemoglobinopathies". In: Wyngaarden JB, Smith LH, eds. Cecil Textbook of Medicine. Philadelphia: WB Saunders (1988): 936-942.

15. P F Milner., et al. "Sickle-cell disease as a cause of osteonecrosis of the femoral head". New England Journal Medicine 325 (1991): 1476-1481.

16. Gaston MHJ I Verter., et al. "Prophylaxis with oral penicillin in children with sickle-cell anemia:A randomized trial". New England Journal Medicine 314 (1986): 1593-1599.

17. John AB., et al. "Prevention of pneumococcal infection in children with homozygous sickle cell disease". British Medical Journal 288 (1984): 1567-1570.
18. Cohen SG and Glick M. "Sickle-cell anemia". In: Rose LF, Kaye D. Internal Medicine for Dentistry. St. Louis: C.V. Mosby Co. (1990): 362-363.

19. Soni NN. "Microradiographic study of dental tissues in sicklecell anemia". Archives of Oral Biology 11.6 (1966): 561-564.

20. Andrews CH., et al. "Sickle cell anemia: An etiological factor in pulpal necrosis”. Journal of Endodontics 9.6 (1983) 249-252.

21. Patton LL., et al. "Mandibular osteomyelitis in a patient with sickle-cell anemia: report of a case". Journal of the American Dental Association 121.5 (1990): 602-604.

22. Shroyer JV., et al. "Osteomyelitis of the mandible as a result of sickle-cell disease". Oral Surgery 72 (1991): 25-28.

23. Neves FS., et al. "Radiographic changes of the jaws in HbSS and HbSC genotypes of sickle cell". Special Care in Dentistry 31.4 (2011): 129-133.

24. Daramola JO. "Massive osteomyelitis of the mandible complicating sickle-cell diseases: report of a case". Journal of Oral Surgery 39.22 (1981): 144-146.

25. Halpern IL. "Patient's medical status--a factor in dental treatment". Oral Surgery, Oral Medicine and Oral Pathology 39.2 (1975): 216-226.

26. Chen $\mathrm{AH}$ and Yee HF. "Improving Primary care specialty care lessons from San Francisco's safety net: comment on referral and consultation communication between primary care and specialist physicians". Archives Intern Medicine 171.1 (2011): 65-67.

27. Mourshed F and Tuckson CR. "A study of radiographic features of the jaws in sickle-cell anemia". Oral Surgery 37 (1974): 812819.

28. Embrack LA. "Dental problems of the sickle-cell anemia patient". Journal of Maryland State Dental Association 111 (1985): 70-74. 
The Efficacy of Medical Consultation to Improve Oral Health Outcomes in Patients with Sickle Cell Disease

29. Yawn BP., et al. "Management of Sickle Cell Disease: Summary of the 2014 Evidence-Based Report by Expert Panel Members". Journal of the American Medical Association 312.10 (2014): 1033-1048.

\section{Assets from publication with us}

- Prompt Acknowledgement after receiving the article

- Thorough Double blinded peer review

- Rapid Publication

- Issue of Publication Certificate

- High visibility of your Published work

Website: www.actascientific.com/

Submit Article: www.actascientific.com/submission.php Email us: editor@actascientific.com

Contact us: +919182824667 